\title{
CORONOFOBIA E AS DESORDENS PSÍQUICAS EMERGENTES NA PANDEMIA: UMA REVISÃO INTEGRATIVA DA LITERATURA
}

\section{CORONAPHOBIA AND PSYCHIC DISORDERS EMERGING IN THE PANDEMIC: AN INTEGRATIVE LITERATURE REVIEW}

\author{
Ludna Pereira Nascimento, ${ }^{1}$ \\ Joyci Pontes dos Santos ${ }^{2}$
}

Maria da Conceição Caetano de Siqueira ${ }^{3}$

RESUMO: INTRODUÇÃO: A pandemia do novo coronavírus (COVID-ı) é a uma emergência de saúde pública que afeta não só o Brasil, mas toda a comunidade internacional. A aflição relacionada aos males que esse vírus traz, vai muito além da saúde física, pois também demonstrou danos na saúde mental de grande parte da população, através do aumento do sofrimento psicológico e a emergência de patologias psiquiátricas, as quais são denominadas por coronofobia. OBJETIVO: O objetivo do presente estudo é descrever a coronofobia como desordem psíquica emergente na pandemia, identificando o quadro clínico, as doenças psiquiátricas mais associadas a ela, a classe mais acometida e possíveis formas de prevenção. METODOLOGIA: Trata-se de uma revisão integrativa da literatura, de caráter descritivo, retrospectivo e qualitativo em que foram utilizadas as bases de dados Scielo, Medscape e PubMed. Aplicou-se como Descritores de Ciência da Saúde (DeCS) as seguintes palavras: "Pandemia da covid 19 " e "Coronaphobia". Foram encontradas 72 publicações nas bases de dados pesquisadas, das quais 30 foram selecionados para leitura e 17 utilizadas para compor este artigo. RESULTADOS E DISCURSÕES: Os resultados apontam que durante a pandemia da COVID-I9 emergiu a coronofobia desordem psíquica vinculada a doenças psiquiátricas, sendo as mais frequentes: depressão, ansiedade generalizada, transtorno do estresse pós-traumático e síndrome do pânico. Esse vínculo, conforme pesquisas científicas, foi mais relatado em pessoas do sexo feminino e adultos jovens. CONCLUSÃO: Logo, ações profiláticas são viáveis e eficazes na tentativa de evitar ou reduzir o impacto da coronofobia na saúde mental na sociedade.

Palavras-chave: Coronavírus. Coronofobia. Saúde mental.

ABSTRACT: INTRODUCTION: The pandemic of the new coronavirus (COVID-19) is a public health emergency that affects not only Brazil, but the entire international community. The affliction related to the evils that this virus brings goes far beyond physical

'Acadêmica de Enfermagem do Centro Universitário da Amazônia UNAMA. Email: ludna-itb@hotmail.com ${ }^{2}$ Acadêmica de Enfermagem do Centro Universitário da Amazônia UNAMA. Email: Joyce.16o8pontes@gmail.com

${ }_{3}^{3}$ Docente do Centro Universitário da Amazônia UNAMA. Email: siqueira_44@hotmail.com. 
health, as it has also shown damage to the mental health of much of the population, through increased psychological suffering and the emergence of psychiatric pathologies, which are accompanied by coronaphobia. OBJECTIVE: The aim of this study is to describe coronaphobia as a psychiatric disorder emerging in the pandemic, identifying the clinical picture, the psychiatric illnesses most associated with it, the most affected class and possible forms of prevention. METHODOLOGY: This is an integrative literature review, descriptive, retrospective and qualitative in which the Scielo, Medscape and PubMed databases were used. The following words were applied as Health Science Descriptors (DeCS): "Pandemia of covid 19" and "Coronaphobia" 19 and its impact on the mental health of Brazilians. For the results, 72 publications were presented in the researched databases, of which 17 were selected for reading, and from these and to compose this article. RESULTS AND DISCOURSIOS: The results indicate that during the pandemic of COVID-I9 there was the phenomenon of coronaphobia linked to the rise of psychiatric illnesses, the most frequent being depression, generalized anxiety, post-traumatic stress disorder, and panic syndrome. This link, according to scientific research, has been reported more often in females and young adults. Therefore, forms of prevention are extremely important, in order to avoid the onset of these disorders, for example, establishing a daily routine, healthy eating, and doing physical exercises. CONCLUSION: It was observed that coronaphobia can be associated with psychiatric illnesses, whether they are previous or not in the individual; furthermore, prophylactic actions are feasible and effective in an attempt to avoid or reduce the impact of coronaphobia on mental health in society.

Keywords: Coronavirus. Coronaphobia. Mental health.

\section{INTRODUÇÃO}

Segundo a Organização Mundial da Saúde (OMS), antes da pandemia do novo Coronovírus o Brasil já era considerado o país mais ansioso do mundo, com a pandemia as pesquisas demonstram aumento nos números de casos, pessoas que antes não apresentavam nenhum problema psíquico, passaram a apresentar alguma instabilidade na saúde mental, relacionados ao humor, medo e perda do autocontrole. É possível ainda perceber que a medida que os anos passam, e o número de pessoas acometidas por covid cresce, os números de casos de pacientes com problemas em saúde mental só aumentam.

A pandemia é um fenômeno mundial, causada pelo vírus SARS-COV̌ e possui particularidades incomparáveis, no sentido de seu crescimento, velocidade, impacto geral na população e nos serviços de saúde. Desde o surgimento da pandemia, a rotina de todos mudou, e cada um, reagiu de forma que, fosse menos estressante e não prejudicasse o seu 
desenvolvimento pessoal e profissional. Desse modo, cada indivíduo em sua particularidade conseguia, conviver em comunidade, sem afetar ou comprometer a saúde.

Para a OMS, a pandemia da Covid-I9 se tornou uma emergência pública de nível internacional, até setembro de 2021 foi contabilizado no mundo um total de 218.205.95I casos confirmados com 4.526.583 evoluindo para óbito (HWO, 202I).

Os fatores epidemiológicos e a pressão midiática gerada pelas informações da crise causada pela COVID-I9, tem havido vigilância aprimorada, investigação adicional e esforços consideráveis para reduzir o contágio endêmico, principalmente em populações de risco, gerando anseios e impactos em contextos de saúde na população, sobretudo, a SAÚDE MENTAL. Vale ressaltar que, segundo Silva, D F, (2020), a epidemiologia da COVID-i9, ao comparar os boletins epidemiológicos, foi observado que a maior parte dos casos estão concentrados na região Sudeste. Dentre o total de óbitos a maioria apresentava pelo menos um fator de risco e a cardiopatia foi a principal comorbidade e a maioria dos indivíduos tinha 60 anos ou mais, com predominância do sexo masculino, (USHER, Et al 2020).

O autor ainda afirma que dois grandes princípios atrelados à situação em saúde enfrentada mundialmente com a COVID-ı9, é o déficit na saúde mental em tempos de pandemia, fazendo emergir a coronofobia, e o desconhecimento acerca da coronofobia. A coronofobia é o medo exacerbado de ser infectado por um vírus potencialmente fatal e vinculado a ela, houve o surgimento de patologias psiquiátricas como depressão, ansiedade generalizada, transtorno do estresse pós-traumático e síndrome do pânico. Logo, é de extrema importância a elaboração e execução de formas de prevenção a saúde mental em detrimento a coronofobia.

Segundo a ministério da saúde o agente etiológico da COVID-i9 é um novo coronavírus, o SARS-CoV-2, da família coronaviridae, o qual pode causar infecções respiratórias de gravidade diversa. Os sintomas mais comuns da COVID-I9 são, febre, cansaço e tosse seca, alguns podem apresentar dores musculares, congestão nasal, dor de cabeça, perda do paladar e olfato, diarreia, vômitos, náuseas e dores na garganta. Dentre as complicações da doença, refere lesão cardíaca aguda, insuficiência cardíaca, miocardite, inflamação vascular e arritmias cardíacas, além da propensão do desenvolvimento de 
coágulos sanguíneos, especialmente nos pulmões, sendo este o responsável pelo desenvolvimento de formas mais graves da doença, o qual pode evoluir para um quadro de tromboembolismo pulmonar. (BRASIL, 202I).

A OMS faz orientações para a população mundial sobre a importância de proteger a si e aos outros, logo, as recomendações de prevenção a fim de reduzir a transmissão e contágio do vírus, como critério de grande relevância é praticar a higiene das mãos com água e sabão, sendo necessário um tempo de 40 a 60 segundos para realização de todo procedimento, utilizar álcool em gel, fazer uso de máscaras, evitar aglomerações e manter uma distância de pelo menos um metro e meio entre os indivíduos. Essas atitudes são indispensáveis para o combate ao vírus, caso contrário, a taxa de transmissão e contágio tende a aumentar e junto a ela o número de óbitos pela doença. (HWO, 2020).

Conforme Ornell (2020), a saúde física da população mediante ao novo agente patogênico é primordial para cada indivíduo, principalmente para os gestores e profissionais da área da saúde. Contudo, os cuidados a saúde mental não podem passar despercebidos nesse momento, sabendo que medidas tomadas, como meios de conter a pandemia, podem causar impactos psicológicos significativos, ocasionando lacunas que impossibilitem desdobramentos relacionados a doença, impactos esses que podem ser mais duradouros e influente que o próprio evento da COVID-ig.

Segundo a Fiocruz, há uma estimativa de que parte de uma população exposta a uma pandemia venha a desenvolver algum tipo de manifestação psicopatológica, (IOC/FIOCRUZ, 2020). Corroborando com o tema o Instituto Oswaldo Cruz (2020), inclui que o medo de adoecer e morrer, perder as pessoas amadas, perder os meios de subsistência ou não poder trabalhar durante o isolamento e ser demitido, ser separado de entes queridos e de cuidadores devido ao regime da quarentena, não receber um suporte financeiro, e transmitir o vírus a outras pessoas, pode contribuir para o adoecimento.

Em estudos realizados por Carvalho et al (2020), as pessoas se assolam pelo medo de ser contaminadas por um agente patológico totalmente desconhecidos e de rápido contagio, potencialmente fatal, podem prejudicar o bem estar e a saúde mental do indivíduo relatos de sintomas de depressão, ansiedade e estresse durante a pandemia foram bastante 
comuns, principalmente em profissionais da área da saúde. Corroborando com o tema Wang et al (2020), declara que os grupos que podem responder mais intensamente ao estresse de uma crise incluem pessoas idosas ou que apresentam comorbidades e profissionais de saúde que atuam na linha de frente, tais acontecimentos geram incertezas que atrapalham o enfrentamento da pandemia.

De acordo com Arora (2020), a chamada "coronofobia", é um termo que vem sendo usado para denominar o medo excessivo de contrair a Covid-19, assim como designar o impacto psicológico e os prejuízos funcionais provocados nas pessoas por esta patologia. Ademais, a autora mostra que há uma relação entre o aumento dos sintomas psíquicos e dos transtornos mentais durante a pandemia os quais podem ocorrer por a ação direta do vírus da Covid-ı9 no sistema nervoso central, assim como os sintomas da coronofobia podem ser desencadeados por experiências traumáticas associadas à infeção, à morte de pessoas próximas e o estresse induzido pela mudança na rotina devido às medidas de distanciamento social.

Relatos da Associação Brasileira de Psiquiatria (ABP), destacam que na fase inicial do surto da pandemia, algumas morbidades e sintomas como quadros de depressão persistente e ansiedade, em algumas situações, ataques de pânico excitações psicomotora, sintomas psicóticos, delírios e até suicídio foram relatados. Em um estudo realizado em 23 estados e Distrito Federal foram entrevistados aproximadamente 400 médicos correspondendo a $8 \%$ do total de psiquiatras do país, mostra que $89,2 \%$ dos especialistas entrevistados destacaram o agravamento de quadros psiquiátricos em seus pacientes devido a pandemia, o levantamento mostra que $47,9 \%$ dos clientes/pacientes tiveram aumento nos atendimentos após o início da pandemia, (ABP, 2021).

Nos estudo realizado por Fortes, (2021) revela que 67,8\% dos médicos receberam pacientes novos que não haviam apresentado sintomas psiquiátricos antes e após o início da pandemia e do isolamento social, outros $69,3 \%$ dos psiquiatras relataram ter atendido pacientes que já haviam recebido alta médica, mas que tiveram recidiva dos sintomas. Com o progresso da pandemia e consequente aumento no número de mortes, boa parte da 
população apresenta um grande sentimento de medo diante do vírus e de suas consequências no organismo humano, medo que pode se exacerbar e evoluir para a coronofobia.

$\mathrm{Na}$ coronofobia é observada uma preocupação demasiada com a sintomatologia da doença, o excesso de buscas por medidas protetivas e a frustração referente a perdas sociais e ocupacionais. No que diz respeito ao impacto psicossocial, ela é capaz de aumentar o sofrimento psicológico em pessoas já acometidas por patologias psiquiátricas ou de tornarse o gatilho para pessoas predispostas à essas doenças, visto que ocasiona variações adicionais em quadros de depressão, ansiedade generalizada e ansiedade por medo da morte, logo, afetará negativamente o bem-estar emocional durante a pandemia. (ARORA, 2020)

Vale ressaltar que, Brooks e Webster (2020), mostram que a quarentena e o isolamento social restringiram e separaram a população, consequentemente auxiliaram no desenvolvimento de, principalmente, sintomas depressivos os quais frequentemente estão associados aos sintomas da coronofobia, inclusive em pessoas que não tinham história de patologias psiquiátricas pregressas.

Entretanto para os autores, mesmo diante de muitas incertezas, a coronofobia pode ser prevenida e trabalhada a partir de medidas simples aplicadas no cotidiano, os quais fazem toda diferença da qualidade de vida da população, mas principalmente, nos grupos mais afetados.

Após esse pressuposto o presente artigo tem como objetivo geral descrever a coronofobia como desordem psíquica emergente na pandemia e objetivos específicos, identificar as patologias psiquiátricas mais associadas à coronofobia; verificar a classe e o gênero mais acometidos e as possíveis formas de prevenção.

\section{METODOLOGIA/MATERIAIS E MÉTODOS}

Trata-se de uma revisão integrativa da literatura, de caráter descritivo, retrospectivo e qualitativo, em que foram utilizadas as bases de dados Scielo, Medscape e PubMed. Aplicou-se como Descritores de Ciência da Saúde (DeCS) as seguintes palavras: "Pandemia da covid 19" e "Coronaphobia" tendo um total de 72 artigos, sendo eles artigos indexados na língua inglesa, espanhola e portuguesa e suas respectivas traduções. 
Os critérios de inclusão utilizados foram: artigos indexados na língua inglesa, espanhola e portuguesa, contendo data associadas, publicados entre 2019 e 202I, sendo produções completas na modalidade de artigos científicos, teses de doutorado, Dissertação de mestrado e Monografia e materiais do Ministério da Saúde OMS, que contemplassem o tema proposto.

Os critérios de exclusão foram: produções incompletas de artigos científicos, não disponíveis gratuitamente, publicados antes de 2019, teses incoerentes com a situação atual e materiais do Ministério da Saúde que não se enquadraram na proposta atual de estudo.

As informações foram coletadas de bancos de dados online, Scielo, Medscape e PubMed, tendo como alvo a emergente coronofobia, relacionada à propagação da COVID I9 e seu impacto na saúde mental dos brasileiros. Para isso o período estabelecido para a identificação dos fatores associados está compreendido em um período entre 2019 a 202I.

Quanto ao risco-benefício do artigo, evidenciou-se que não há riscos significativos, visto que se trata de uma pesquisa em base de dados, sem envolver de forma direta os seres humanos. Já em relação aos benefícios, a presente pesquisa demonstra vantagens por permitir esclarecer a coronofobia, faz uma análise aprofundada sobre a patologia, oferece canal de comunicação imparcial a fim de refletir sobre esse problema atual de saúde pública e incentiva estratégias de prevenção a ela.

Como se trata de uma pesquisa com a utilização de dados de domínio público, o presente trabalho não passara pela avaliação do Comitê de Ética e Pesquisa, mas serão analisados todos os conteúdos, respeitando os princípios éticos estabelecidos na resolução $466 / 2012$.

\section{RESULTADOS E DISCUSSÃO}

Foram encontradas 72 produções nas bases de dados pesquisadas, das quais 17 foram selecionados para análise do texto na integra. Os artigos selecionados são restritos às bases de dados SCIELO, PUBMED e MEDSCAPE, artigos científicos, revistas de enfermagem, teses de mestrado e doutorado, publicações de congressos com pesquisas atualizadas, como mostra a tabela $\mathrm{I}$. 
Tabela I - Quantitativo de artigos encontrados nas bases de dados eletrônicas.

\begin{tabular}{|l|c|c|c|c|}
\hline Base de Dados & MEDSCAPE & PUBMED & SCIELO & TOTAL \\
\hline Produção encontrada & 18 & 36 & 18 & 72 \\
\hline Títulos Selecionados & $\mathbf{I}$ & 4 & 12 & 17 \\
\hline
\end{tabular}

Fonte: SCIELO; PUBMED; MEDSCAPE, 2019 a 2021.

$\mathrm{Na}$ finalidade de melhor apresentar e facilitar a compreensão, o resultado e discursão foi organizado por temáticas, e as pesquisas que satisfizeram os critérios de inclusão foram organizadas em um quadro (Quadro I) de forma codificada por sequência alfanumérica, no intervalo de $\mathrm{C}_{\mathrm{r}}$ a $\mathrm{C}_{17}$, a letra $\mathrm{C}$ foi escolhida por se tratar da primeira letra da palavra Covid. Os estudos estão classificados de acordo com o autor/ano; local de publicação; título do estudo e objetivo do estudo.

Quadro I. Perfil das referências

\begin{tabular}{|c|c|c|c|c|}
\hline Número & Autor/ Ano & $\begin{array}{l}\text { Local da } \\
\text { publicação }\end{array}$ & Título do estudo & $\begin{array}{l}\text { Objetivos do } \\
\text { estudo }\end{array}$ \\
\hline $\mathrm{C}_{\mathrm{I}}$ & $\begin{array}{c}\text { Arora, a; Jha, a k; } \\
\text { Alat, p/2020 }\end{array}$ & Pubmed & $\begin{array}{l}\text { Compreendendo } \\
\text { a coronofobia }\end{array}$ & $\begin{array}{ll}\text { Descrever } & \text { os } \\
\text { aspectos } & \mathrm{da} \\
\text { coronofobia. } & \end{array}$ \\
\hline $\mathrm{C}_{2}$ & $\begin{array}{c}\text { Associação } \\
\text { Brasileira de } \\
\text { psiquiatria/202I }\end{array}$ & $\begin{array}{c}\text { Scielo } \\
\text { Associação } \\
\text { Brasileira de } \\
\text { psiquiatria }\end{array}$ & $\begin{array}{l}\text { Atendimentos } \\
\text { psiquiátricos no } \\
\text { Brasil sofrem } \\
\text { impacto da } \\
\text { pandemia de } \\
\text { Covid-i9. }\end{array}$ & $\begin{array}{l}\text { Relatar } \\
\text { epidemiologia dos } \\
\text { casos } \\
\text { psiquiátricos } \\
\text { afetados com a } \\
\text { pandemia } \\
\text { formas } \\
\text { prevenção. }\end{array}$ \\
\hline
\end{tabular}




\begin{tabular}{|c|c|c|c|c|}
\hline $\mathrm{C}_{3}$ & $\begin{array}{l}\text { Brasil ministério } \\
\text { da saúde/2020 }\end{array}$ & $\begin{array}{c}\text { Scielo } \\
\text { Ministério da } \\
\text { saúde }\end{array}$ & $\begin{array}{l}\text { Saúde mental e a } \\
\text { covid-r9 }\end{array}$ & $\begin{array}{l}\text { Avaliar as } \\
\text { repercussões } \\
\text { negativas na } \\
\text { saúde mental dos } \\
\text { brasileiros, que } \\
\text { tende à evoluir } \\
\text { para quadros de } \\
\text { coronofobia } \\
\text { durante } \\
\text { pandemia do } \\
\text { coronavirus e } \\
\text { relatar formas de } \\
\text { prevenção }\end{array}$ \\
\hline $\mathrm{C}_{4}$ & Brooks et al./2020 & Scielo & $\begin{array}{l}\text { Impactos na } \\
\text { saúde mental e } \\
\text { intervenções } \\
\text { psicológicas } \\
\text { diante da } \\
\text { pandemia do } \\
\text { novo } \\
\text { coronavírus }\end{array}$ & $\begin{array}{l}\text { Identificar as } \\
\text { patologias } \\
\text { psiquiátricas mais } \\
\text { recorrentes nos } \\
\text { brasileiros } \\
\text { durante } \\
\text { pandemia da } \\
\text { COVID-I9. }\end{array}$ \\
\hline $\mathrm{C}_{5}$ & $\begin{array}{c}\text { Brooks, S. K., } \\
\text { Webster, R. } \\
\text { K.C./2020 }\end{array}$ & Scielo & $\begin{array}{l}\text { O impacto } \\
\text { psicológico da } \\
\text { quarentena e } \\
\text { como reduzi-lo: } \\
\text { revisão rápida } \\
\text { das evidências }\end{array}$ & $\begin{array}{l}\text { Analisar e } \\
\text { descrever quais } \\
\text { foram os } \\
\text { impactos } \\
\text { psicológicos } \\
\text { negativos e a } \\
\text { sintomatologia } \\
\text { que foram }\end{array}$ \\
\hline
\end{tabular}




\begin{tabular}{|c|c|c|c|c|}
\hline & & & & $\begin{array}{l}\text { observados } \\
\text { durante } \\
\text { momento da } \\
\text { quarentena e do } \\
\text { isolamento social. }\end{array}$ \\
\hline C6 & $\begin{array}{c}\text { Campos, Mônica } \\
\text { Rodrigues et } \\
\text { al/2020 }\end{array}$ & Scielo & $\begin{array}{l}\text { Carga de doença } \\
\text { da COVID-ıg e } \\
\text { de suas } \\
\text { complicações } \\
\text { agudas e } \\
\text { crônicas: } \\
\text { reflexões sobre a } \\
\text { mensuração } \\
\text { (DALY) } \\
\text { perspectivas no } \\
\text { Sistema Único } \\
\text { de Saúde. }\end{array}$ & $\begin{array}{l}\text { Citar de forma } \\
\text { breve as } \\
\text { complicações da } \\
\text { COVID i9 e a } \\
\text { faixa etária } \\
\text { acometida. }\end{array}$ \\
\hline $\mathrm{C}_{7}$ & $\begin{array}{l}\text { Carvalho, P. M. } \\
\text { M, Et al/2020 }\end{array}$ & $\begin{array}{l}\text { Pubmed } \\
\text { Psychiatry } \\
\text { Research }\end{array}$ & $\begin{array}{l}\text { O impacto } \\
\text { psiquiátrico do } \\
\text { novo surto de } \\
\text { coronavírus }\end{array}$ & $\begin{array}{l}\text { Descrever sobre o } \\
\text { impacto da a } \\
\text { coronofobia e } \\
\text { sintomatologia } \\
\text { associada. }\end{array}$ \\
\hline $\mathrm{C} 8$ & $\begin{array}{c}\text { FORTES, A B. et } \\
\text { al/2021 }\end{array}$ & $\begin{array}{c}\text { Scielo } \\
\text { Ministério da } \\
\text { saúde }\end{array}$ & $\begin{array}{l}\text { COVID I9: guia } \\
\text { orientador para } \\
\text { enfrentamento } \\
\text { da pandemia na } \\
\text { Rede de Atenção } \\
\text { à saúde. }\end{array}$ & $\begin{array}{l}\text { Coletar dados } \\
\text { numéricos } \\
\text { percentual quanto } \\
\text { ao aparecimento } \\
\text { de sintomas } \\
\text { psíquicos tanto na } \\
\text { população em }\end{array}$ \\
\hline
\end{tabular}




\begin{tabular}{|c|c|c|c|c|}
\hline & & & & $\begin{array}{l}\text { geral, quanto em } \\
\text { profissionais da } \\
\text { área da saúde. }\end{array}$ \\
\hline $\mathrm{C}_{9}$ & $\begin{array}{c}\text { Instituto Oswaldo } \\
\text { Cruz/2020 }\end{array}$ & Scielo & $\begin{array}{l}\text { Saúde mental e } \\
\text { atenção } \\
\text { psicossocial na } \\
\text { pandemia } \\
\text { COVID iq }\end{array}$ & $\begin{array}{l}\text { Citar alguns } \\
\text { sintomas } \\
\text { correspondentes a } \\
\text { coronafobia. }\end{array}$ \\
\hline Cio & Jung \& Jun/2020 & Scielo & $\begin{array}{l}\text { Saúde mental e } \\
\text { intervenção } \\
\text { psicológica em } \\
\text { meio ao surto de } \\
\text { COVID-ıg: } \\
\text { perspectivas da } \\
\text { Coreia do Sul }\end{array}$ & $\begin{array}{l}\text { Relatar casos de } \\
\text { suicídio durante a } \\
\text { pandemia que } \\
\text { estão relacionadas } \\
\text { a coronpfobia e as } \\
\text { doenças psíquicas } \\
\text { emergentes e } \\
\text { formas de evitar o } \\
\text { acometimento. }\end{array}$ \\
\hline $\mathrm{C}_{\mathrm{II}}$ & $\begin{array}{c}\text { Limcaoco, Mateos, } \\
\text { Fernandez, \& } \\
\text { Roncero/2020 }\end{array}$ & Scielo & $\begin{array}{l}\text { Ansiedade, } \\
\text { preocupação e } \\
\text { estresse } \\
\text { percebido no } \\
\text { mundo devido à } \\
\text { pandemia } \\
\text { COVID-ı9 }\end{array}$ & $\begin{array}{l}\text { Identificar a faixa } \\
\text { etária e o gênero } \\
\text { mais acometidos } \\
\text { pela coronofobia } \\
\text { em pesquisas } \\
\text { científicas. }\end{array}$ \\
\hline $\mathrm{C}_{12}$ & $\begin{array}{c}\text { Ornell, F, Et } \\
\text { al./2020 }\end{array}$ & $\begin{array}{c}\text { Pubmed } \\
\text { Brazilian } \\
\text { Journal of } \\
\text { Psychiatry } \\
\text { Retrieved }\end{array}$ & $\begin{array}{l}\text { "Medo } \\
\text { pandêmico" } \\
\text { COVID-ı9: } \\
\text { carga }\end{array}$ & $\begin{array}{l}\text { Citar os impactos } \\
\text { na saúde mental } \\
\text { durante } \\
\text { pandemia. }\end{array}$ \\
\hline
\end{tabular}




\begin{tabular}{|c|c|c|c|c|}
\hline & & & $\begin{array}{l}\text { estratégias de } \\
\text { saúde mental }\end{array}$ & \\
\hline $\mathrm{C}_{13}$ & $\begin{array}{c}\text { Schmidt, B. et } \\
\text { al/2020 }\end{array}$ & Scielo & $\begin{array}{l}\text { Saúde mental e } \\
\text { intervenções } \\
\text { psicológicas } \\
\text { diante da } \\
\text { pandemia do } \\
\text { novo } \\
\text { coronavírus } \\
\text { (COVID-ı9). }\end{array}$ & $\begin{array}{l}\text { Identificar a } \\
\text { sintomatologia e } \\
\text { as patologias } \\
\text { psiquiátricas mais } \\
\text { frequentes } \\
\text { durante o período } \\
\text { da pandemia e sua } \\
\text { correlação com a } \\
\text { coronofobia. }\end{array}$ \\
\hline $\mathrm{C}_{14}$ & Taylor, S/2019 & Scielo & $\begin{array}{l}\text { A psicologia das } \\
\text { pandemias: } \\
\text { preparando-se } \\
\text { para o próximo } \\
\text { surto global de } \\
\text { doenças } \\
\text { infecciosas }\end{array}$ & $\begin{array}{l}\text { Descrever } \\
\text { coronofobia } \\
\text { comparar } \\
\text { impacto físico e } \\
\text { mental da doença. }\end{array}$ \\
\hline $\mathrm{C}_{15}$ & $\begin{array}{c}\text { Usher K, Et } \\
\text { al/2020 }\end{array}$ & Pubmed & $\begin{array}{l}\text { A vida na } \\
\text { pandemia: } \\
\text { isolamento } \\
\text { social e saúde } \\
\text { mental }\end{array}$ & $\begin{array}{l}\text { Citar os impactos } \\
\text { na saúde mental } \\
\text { durante } \\
\text { isolamento na } \\
\text { pandemia. }\end{array}$ \\
\hline
\end{tabular}




\begin{tabular}{|c|c|c|c|c|}
\hline Ci6 & Wang $\mathrm{d}$, et $\mathrm{al} / 2020$ & Scielo & $\begin{array}{l}\text { Características } \\
\text { clínicas de } \\
\text { pacientes } \\
\text { hospitalizados } \\
\text { com nova } \\
\text { pneumonia } \\
\text { infectada por } \\
\text { coronavírus de } \\
\text { 2oig em Wuhan, } \\
\text { China }\end{array}$ & $\begin{array}{l}\text { Citar algumas } \\
\text { patologias } \\
\text { psiquiátricas } \\
\text { emergentes } \\
\text { durante } \\
\text { pandemia em } \\
\text { pacientes } \\
\text { hospitalizados. }\end{array}$ \\
\hline $\mathrm{C}_{17}$ & Watson J./2020 & Medscape & $\begin{array}{l}\text { O impacto } \\
\text { psicológico da } \\
\text { Covid-ı ganha } \\
\text { nome }\end{array}$ & $\begin{array}{l}\text { Analisar os } \\
\text { sintomas físicos } \\
\text { das patologias } \\
\text { psiquiátricas } \\
\text { atreladas a } \\
\text { coronofobia. }\end{array}$ \\
\hline
\end{tabular}

Fonte: SCIELO, PUBMED e MEDSCAPE - 2019 a 2021.

\section{DESORDEM PSÍQUICAS EMERGENTE NA PANDEMIA}

Arora (2020) (CI), Ornell et al. (2020) ( $\mathrm{C}_{12}$ ) relatam no estudo que os sentimentos mais comuns, como o medo de morrer, de perder o emprego, familiares e amigos, causam sentimento de desesperança, paranoias, angustias, e até ideação suicida, e estão associados diretamente com a coronofobia, dificultando o modo de vida das pessoas.

Corroborando com esses estudo, Fortes et al (2021) (C8), Shimidt et al (2020) (C13), concluiu que com o crescimento da pandemia, o grande foco da saúde pública foi o combate ao agente patogênico, de modo que a saúde mental foi "esquecida". Esse fato, gerou disfunções importantes no enfrentamento dos danos psicológicos associados à doença, visto que esses prejuízos estão presentes em diversos setores sociais e faixas etárias, e podem ser 
inclusive, muito mais duradouros quando comparados aos acometimento físico causado pelo vírus.

Taylor (2019)(Ci4); Ornell et al (2020) ( $\mathrm{C}_{12}$ ) e Watson (2020) ( $\left.\mathrm{C}_{17}\right)$ descrevem em seu estudo como o medo exacerbado de ser infectado por um vírus potencialmente fatal, de rápida transmissão e propagação, afeta o psicológico de muitas pessoas, considerando que até o momento a doença não tem um tratamento eficaz e as sequelas perduram por meses, dessa forma as pessoas desenvolvem sintomas como, medo de morrer, de infectar familiares e amigos, de afastamento ou abandono nas relações sociais, estresse, sensação de perda de controle, estigmatização da doença, além de preocupação com o tempo de duração da pandemia, tais sintomas provocou na população, uma sintomatologia tanto física, quando psíquica.

No estudo realizado por Watson, (2020) $\left(\mathrm{C}_{17}\right)$, o autor enfatiza que a coronofobia é caracterizada pelo medo que surgiu nas pessoas relacionado a extensão da pandemia, ocasionando uma ansiedade generalizada, depressão profunda e até ideação suicida, os indivíduos passam a experimentar tais sintomas desagradáveis desencadeados por pensamentos e informações recebidos sobre a doença.

Carvalho et al. (2020) ( $\left.\mathrm{C}_{7}\right)$ e Instituto Oswaldo Cruz (2020) (C9) realizou uma pesquisa, na qual relata que a coronofobia contribui para a intensificação dos quadros clínicos de doenças e sentimentos pré-existentes, sendo eles psíquicos e/ou físicos, por exemplo, paranoia, lembranças e flashbacks de traumas já vivenciados, irritabilidade, raiva, amnésia dissociativa, humor deprimido, perda do interesse ou prazer, insônia ou hipersonia, redução da energia e do apetite, sensação de abandono, culpa e inutilidade, inquietação, fadiga, taquicardia, sudorese, tremores, parestesias, náuseas e vômitos, tontura, vertigem e síncope. As manifestações clinicas supracitadas, estão fortemente relacionadas a coronofobia, gerando um aglomerado de incertezas, sobre o que se pode ainda vivenciar com a pandemia de covid -ı, fazendo uma rápida analogias sobre outras epidemias históricas.

Corroborando com o tema Shimidt et al (2020) ( $\left.\mathrm{C}_{13}\right)$ enfatiza que o toda a ansiedade relacionada a pandemia, ou sobre qualquer outra doença infecciosa, desencadeia a hipocondria, e se torna uma doença duradoura, tornando o indivíduo portador, a apresentar 
problemas mentais, por apresentar uma forte relação com a depressão e a ansiedade, portanto, acredita-se que o fator de vulnerabilidade e medo desencadeou algumas psicopatologia durante a pandemia de COVID-ig.

$\mathrm{Na}$ pesquisa de Jung \& Jun, (2020) (Cio), Wang et al. (2020) (Ci6) o autor correlaciona também, a coronofobia com o sofrimento emocional e fatores externos como o alcoolismo, uso de substâncias psicoativas, e a considerável desesperança em uma grande parte da população ansiosa e preocupadas com os acontecimentos causados pelo coronavírus. De maneira geral, os autores reforçam a afirmação que a pandemia do novo corona vírus, possui fatores adicionais para o desenvolvimento de estresse e transtornos mentais, pois além da preocupação em exercer as atividades diárias, como trabalhar, estudar, os indivíduos ainda devem conviver com o medo de contrair a doença.

\section{PATOLOGIAS PSIQUIÁTRICAS ASSOCIADAS À CORONOFOBIA}

Brooks et al (2020) ( $\left.\mathrm{C}_{4}\right)$, quando se refere a coronofobia como uma desordem emergente, cita a ansiedade generalizada, e quadros de depressão como fatores associados a essa desordem. O medo da morte e a preocupação em contrair a infecção, elevam o sentimento de desesperança, acarretando assim, um forte gatilho para um transtorno mental, comprometendo a sua disposição ao enfretamento da COVID-ı.

De acordo com os estudos de Wang et al (2020) (C16) Usher et al (2020) (C15) foi identificado com bastante frequência na população geral durante a pandemia o surgimento ou agravamento de sintomas de depressão, ansiedade generalizada, transtorno do estresse pós-traumático e síndrome do pânico, se tornando assim, as patologias mais emergentes durante a pandemia.

Concordando com os autores, Watson (2020) ( $\left.\mathrm{C}_{17}\right)$, relata que as situações vividas com a pandemia do novo coronavirus, desencadeia sentimentos, que em alguns manifestamse de forma branda e em outros de forma crônica, tornando-os mais suscetíveis a experimentar momentos de desespero e solidão, levando-os a acreditar que existe uma barreira ao enfrentamento da pandemia, esses sentimentos quando descompensados, são associados a coronofobia. 


\section{CLASSES E GÊNEROS ACOMETIDOS}

Limcaoco, Mateos, Fernandez, \& Roncero (2020) (CiI) relatam em estudo realizado com pessoas em mais de 40 países que o grupo mais acometido pela coronofobia, foi no gênero feminino e nas faixas etárias mais jovens, como adolescentes e adultos jovens. Sendo assim, esse grupo se mostrou como um preditor significativo para maior nível de estresse durante a pandemia e consequentemente o que teve mais sintomas, sejam eles psíquicos ou físicos, atrelados as patologias psiquiátricas pregressas ou não.

Campos et al (2020) (C6) Brooks S (2020) ( $\mathrm{C}_{5}$ ) corrobora descrevendo que os fatores que podem tornar uma determinada classe mais suscetível, vai depender de características definidoras, como a história de vida, suas particularidades, a comunidade que vive e sua formação. Seguindo esse princípio, além dos jovens e adolescentes, os profissionais da saúde, forma o grupo mais acometido por esse transtorno por estarem diretamente ligados ao atendimento a vítimas da covid - 19, pessoas que já possuem transtornos mentais,

principalmente estando relacionado ao uso de substancias improprias forma o que seria denominado o outro grupo. $\mathrm{O}$ autor ainda afirma que, quando comparados com a população em geral, os grupos citados e a faixa etária acometida, mostraram se mais predispostas ao acometimento de transtornos mentias, como a ansiedade generalizada, e a profunda depressão, sendo esses os fatores de desencadeiam a coronofobia.

Reforçando essas evidências, Moreira (2020), menciona uma pesquisa realizada com I8 mil brasileiros com uma idade média de 20 a 40 anos de idade durante o mês de maio de 2020, período no qual houve um aumento de casos de mortes pelo coronavirus, onde revelou que a cada dez pessoas, oito sofriam com quadro de ansiedade generalizada, correlacionada a coronofobia. Relata também, em uma segunda pesquisa feita em algumas universidades do Brasil, que jovens, mulheres e pessoas com diagnósticos prévios de doença mental, foram os que mais sofreram com o impacto da pandemia, e predispostas a coronofobia.

\section{POSSÍVEIS FORMAS DE PREVENÇÃO}

O Ministério da Saúde $\left(C_{3}\right)$, orienta que as formas de prevenção devem ser orientadas a toda a população durante o momento atual da pandemia do coronavírus, visto 
que convém adotar precocemente estratégias de enfrentamento, as quais podem ser individuais e coletivas, que permitam uma a adaptação à realidade do distanciamento social, da quarentena e do atual cenário da COVID-19, reduzindo assim os impactos psicológicos negativos nas pessoas. Simples planejamentos como, estabelecer uma rotina diária, alimentação saudável e equilibrada, realizar exercícios físicos, cognitivos e de relaxamento, ajudam no enfrentamento do estresse, pois há uma sensação de controle na tomada de decisões de maneira consciente, além de manter uma boa saúde física e sensação de bemestar.

A ABP, (202I) ( $\left.\mathrm{C}_{2}\right)$, contribui para o estudo citando alguns meios de prevenir o desenvolvimento desses transtornos, os quais refere, eleger alguns canais de comunicação confiáveis para buscar notícias e questionar as informações para que possam ser verificadas, a fim de não ter contato com notícias falsas, amplamente divulgadas e que podem aumentar a sensação de angustia, ressalta ainda que o excesso de informações, mesmo que verdadeiras, podem aumentar a sensação de ansiedade e angústia, logo, orienta-se que ao pesquisar sobre as atualizações da pandemia, preestabeleça um curto período de tempo para se inteirar das atualizações.

Segundo os resultados encontrados por Jung \& Jun (2020) (Cio), é relevante estabelecer um tempo de convivência com os moradores da casa, para momentos de lazer, podendo ser uma maneira de estabelecer contato com os moradores da mesma casa de forma saudável, reduzindo as tensões e conflitos, entretanto quando não há essa possibilidade, estabelecer contatos telefônicos ou on-line, também é uma alternativa para reduzir a sensação de angustia, abandono e solidão.

Os autores corroboram entre si que, vincular-se e participar de grupos de apoio online ou buscar apoio especializado é primordial para auxiliar no processo de estabilização emocional e, consequentemente, um desfecho favorável em termos de saúde mental, evitando e controlando a coronofobia e os sintomas de patologias psiquiátricas associadas. 


\section{CONSIDERAÇÕES FINAIS}

$O$ atual estudo retratou a coronofobia e as doenças psiquiátricas emergentes durante a pandemia da COVID 19, tendo concordância geral dos autores que explanaram sobre a coronofobia que as sensações e quadros mais comuns relacionado a esse transtorno, incluem a depressão, ansiedade generalizada, transtorno do pânico e paranóias. Diante disso, a partir da análise teórica dos artigos científicos selecionados, percebeu-se um vínculo entre a coronofobia e o aumento no número de casos notificados dessas patologias, principalmente no gênero feminino e nos adultos jovens. Logo, é notório que faltam iniciativas estatais a fim de estimular o cuidado não só com a saúde física, mas também com a saúde mental, visto que as patologias psíquicas afetam negativamente o bem-estar da sociedade e podem deixar sequelas.

A partir das observações, sabe-se que existe uma determinada quantidade de potenciais desencadeantes de transtornos mentais na população. Com isso, há uma necessidade de intervir sobre esses fatores, sendo está uma forma de promover a saúde mental e física desse grupo de pessoas, levando em conta que os mesmos precisam de uma nova perspectiva de vida.

Com base nas considerações expostas, sugere-se, como ferramentas de promoção da saúde mental, já retratadas anteriormente, para toda população, medidas simples e eficazes, a partir da busca de ajuda especializada com profissionais habilitados para ajuda-los na melhoria da qualidade de vida. Assim como a adoção de atitudes simples como, estabelecer uma rotina diária, alimentação saudável e equilibrada, realizar exercícios físicos, eleger alguns canais de comunicação confiáveis para buscar notícias e questionar as informações para que possam ser verificadas, são medidas preventivas que ajudarão as pessoas a encontrar o equilíbrio necessário para conviver com a nova realidade, o que ajudará a reduzir a quantidade de casos, tanto da coronofobia, quanto das doenças psiquiátricas emergentes.

Por se tratar de uma doença emergente, vale ressaltar ainda que essa mesma população necessita de uma atenção especial, cuidados e apoio por parte de toda a sociedade, sendo assim, é imprescindível que a academia se proponha a elabore mais trabalhos e estudos sobre 
o tema abordando reforçando os principais fatores que levam as consequências da pandemia assim como as medidas preventivas.

\section{REFERÊNCIAS BIBLIOGRÁFICAS}

ARORA A, Jha, A K, Alat, P. Understanding coronaphobia. Asian J Psychiatr. 2020 Dec;54:102384. doi: ro.1o16/j.ajp.2020.102384. Epub 2020 Sep 6. PMID: 33271693; PMCID: $\mathrm{PMC}_{7474809 .}$

ASSOCIAÇÃO BRASILEIRA DE PSIQUIATRIA. Atendimentos psiquiátricos no Brasil sofrem impacto da pandemia de Covid-19. Rio de Janeiro. 202I acessado em oI/o5/202I BRASIL. Ministério da saúde. Saúde mental e a COVID-19 (2020). Publicado pelo site do ministério da saúde. Disponível em http://bvsms.saude.gov.br/ultimas-noticias/3427 Acessado em or/o5/2021

BROOKS ET AL., (2020). Impactos na Saúde Mental e Intervenções Psicológicas Diante da Pandemia do Novo Coronavírus. Publicado pelo site Scielo. Disponível em https://doi.org/10.1590/1982-0275202037e200063. Acessado em ol/o5/2021

BROOKS, S. K., WEBSTER, R. K.CESARINO, (2020). O impacto psicológico da quarentena e como reduzi-lo: revisão rápida das evidências. Publicado pelo site SCIELO. Disponível em » https://doi.org/ro.ror6/Sor40-6736(20)3046o-8>. Acessado em or/o5/2021 as I9:ooh

CAMPOS, Mônica Rodrigues et al. Carga de doença da COVID-ıg e de suas complicações agudas e crônicas: reflexões sobre a mensuração (DALY) e perspectivas no Sistema Único de Saúde. Cadernos de Saúde Pública [online], 2020. v. 36, n. II [Acessado 23 Novembro 2021] , eoor48920. Disponível em: 〈https://doi.org/10.1590/oro2-31IXooI48920〉. ISSN I6784464. https://doi.org/ro.1590/oro2-311Xoo148920. 
CARVALHO, P. M. M., Moreira, M. M., Oliveira, M. N. A., Landim, J. M. M., \& Rolim Neto, M. L. (2020). The psychiatric impact of the novel coronavirus outbreak. Psychiatry Research, 286(II2902), I-2. http://dx.doi.org/I0.1016/j.psychres.2020.112902 acesso em $2 \mathrm{I} / \mathrm{10} / 2021$

FUNDAÇÃO OSW ALDO CRUZ. 2020. Saúde mental e atenção psicossocial na pandemia COVID 19. Scielo. Disponivel em: https://www.fiocruzbrasilia.fiocruz.br/wpcontent/uploads/2020/04/Sa\%C3\%BAde-Mental-e-Aten\%C3\%A 7\%C3\%A30-Psicossocialna-Pandemia-Covid-I9-recomenda\% $\mathrm{C}_{3 \% \mathrm{~A}}$ 7\%C3\%B5es-gerais.pdf .Acesso em: 23/II/2I

FORTES, A B. et al. COVID rg: guia orientador para enfrentamento da pandemia na Rede de Atenção à saúde. 4⿳亠丷a edição. Ministério da Saúde. Brasília, 2021 acesso em 2I/Io/202I

JUNG, S. J., \& Jun, J. Y. (2020). Mental health and psychological intervention amid COVID-19 Outbreak: perspectives from South Korea. Yonsei Medical Journal, 6I(4), 27I272. http://dx.doi.org/I0.3349/ymj.2020.61.4.27I aceso em 30/10/202I

LIMCAOCO, R S G, Mateos, E M, Fernández, J M, Roncero, C. Anxiety, worry and perceived stress in the world due to the COVID-19 pandemic, March 2020. Preliminary results The International Journal of Psychiatry in Medicine doi:10.1177/oog12174211033710 acesso em ol/II/202I

MOREIRA, M. M., Oliveira, M. N. A., Landim, J. M. M., \& Rolim Neto, M. L. (2020). The psychiatric impact of the novel coronavirus outbreak. Psychiatry Research, 286(II2902), I-2. http://dx.doi.org/ro.IoI6/j.psychres.2020.112902 acesso em 2I/II/202I

HWO 202I Noticias sobre o novo Corona Virus. Disponível em: https://www.paho.org/pt/covidig/historico-da-pandemia-covid-I9. Acesso em oI/II/202I 
ORNELL F, Schuch JB, Sordi AO, Kessler FHP. "Pandemic fear" and COVID-rg: mental health burden and strategies. Braz J Psychiatry.2020;42(3):232-2357 acesso em Io/II/202I

SCHMIDT, B., Crepaldi, M. A., Bolze, S. D. A., Neiva-Silva, L., \& Demenech, L. M. (2020). Saúde mental e intervenções psicológicas diante da pandemia do novo coronavírus (COVID-19). Estudos de Psicologia (Campinas), 37, e200063.http://dx.doi.org/10.1590/1982-0275202037e200063 acesso em Io/II/2021 TAYLOR, S. (2019). The psychology of pandemics: preparing for the next global outbreak of infectious disease Newcastle upon Tyne: Cambridge Scholars Publishing. Acesso em I4/ II/ 202I

USHER K, Bhullar N, Jackson D. Life in the pandemic: Social isolation and mental health. J Clin Nurs. 2020 Aug;29(15-16):2756-2757. doi: Io.III/jocn.15290. Epub 2020 May 6. PMID: 32250493 acesso em I4/ II/ 2021

WANG D, ET AL (2020). Características clínicas de pacientes hospitalizados com nova pneumonia infectada por coronavírus de $2019 \mathrm{em}$ Wuhan, China. Publicado pelo site Scielo. Disponível em https://preprints.scielo.org/index.php/scielo/preprint/view/58. Acesso em i5/II/202I.

WATSON J. Covid-rg's Psychological Impact Gets a Name. Medscape, September 29th, 2020. Disponível em: https://www.medscape.com/viewarticle/938253 acesso em I5/II/202I 